\title{
The role of noninvasive ventilation in the management of type II respiratory failure in patients with myotonic dystrophy
}

\author{
Vilma Rautemaa $\mathbb{Q}^{1}$, Mark E. Roberts ${ }^{2}$, Andrew Bentley ${ }^{3,4}$ and Timothy W. Felton ${ }^{3,4}$
}

${ }^{1}$ School of Medical Sciences, Faculty of Biology, Medicine and Health, The University of Manchester, Manchester, UK. ${ }^{2}$ Dept of Neurology, Greater Manchester Neurosciences Centre, Salford Royal NHS Foundation Trust, Salford, UK. ${ }^{3}$ North West Ventilation Unit, Manchester University NHS Foundation Trust, Manchester, UK. ${ }^{4}$ Division of Infection, Immunity and Respiratory Medicine, School of Biological Sciences, Faculty of Biology, Medicine and Health, The University of Manchester, Manchester, UK.

Corresponding author: Tim Felton (tim.felton@manchester.ac.uk)

Shareable abstract (@ERSpublications)

Commencing patients with myotonic dystrophy on noninvasive ventilation appears to reverse respiratory failure despite poor adherence to ventilation https://bit.ly/343XUGK

Cite this article as: Rautemaa V, Roberts ME, Bentley A, et al. The role of noninvasive ventilation in the management of type II respiratory failure in patients with myotonic dystrophy. ERJ Open Res 2021; 7 : 00192-2020 [DOI: 10.1183/23120541.00192-2020].

Copyright (The authors 2021

This version is distributed under the terms of the Creative Commons Attribution NonCommercial Licence 4.0. For commercial reproduction rights and permissions contact permissions@ersnet.org

Received: 17 April 2020 Accepted: 16 May 2021

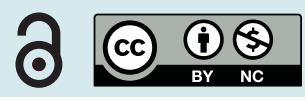

\section{Abstract}

Type 1 myotonic dystrophy (DM1) causes sleep disordered breathing and respiratory failure due to a combination of obstructive sleep apnoea, reduced central drive and respiratory muscle weakness. Noninvasive ventilation (NIV) is commonly used for treating respiratory failure in neuromuscular disease; however, there have been few studies assessing the role of NIV in DM1. The aim of this retrospective service evaluation was to investigate the impact of NIV adherence on hypercapnia and symptoms of hypoventilation in patients with DM1. Data on capillary carbon dioxide tension $\left(P_{\mathrm{CO}_{2}}\right)$, lung function, adherence to NIV and symptoms of hypoventilation were obtained from the records of 40 patients with DM1. Mean capillary $P_{\mathrm{CO}_{2}}$ significantly reduced from $6.81 \pm 1.17 \mathrm{kPa}$ during supervised inpatient set-up to $5.93 \pm 0.82 \mathrm{kPa}$ after NIV set-up $(\mathrm{p}<0.001)$. NIV adherence reduced from 7.8 (range: $1.0-11.0$ ) h per $24 \mathrm{~h}$ during supervised inpatient set-up to $2.9(0-10.4) \mathrm{h}$ per $24 \mathrm{~h}$ in the community. Overall $72 \%$ of patients used NIV $<5$ h per $24 \mathrm{~h}$ during follow-up, including $11 \%$ who discontinued NIV completely. There was no correlation between adherence to NIV and changes in capillary $P_{\mathrm{CO}_{2}}$. Patients who reported symptomatic benefit $(50 \%)$ had higher adherence than those who did not feel benefit $(\mathrm{p}<0.05)$. In conclusion, in patients with myotonic dystrophy with Type II respiratory failure maintaining adherence is challenging.

\section{Introduction}

Type 1 myotonic dystrophy (DM1) is an autosomal dominant disease caused by a CTG trinucleotide repeat expansion in the dystrophia myotonica protein kinase (DMPK) gene on chromosome 19. It is the most common muscular dystrophy in adults of European ancestry, with prevalence of DM1 ranging from 10 to 18/100000 [1, 2]. The clinical features of DM1 include progressive myotonia and muscle weakness, as well as variable multisystem involvement such respiratory failure, cataracts, cardiac conduction abnormalities, daytime somnolence and cognitive defects. Respiratory failure occurs due to a combination of respiratory muscle weakness, reduced central drive, insensitivity to carbon dioxide $\left(\mathrm{CO}_{2}\right)$, upper airway obstruction and reduced chest wall compliance [3, 4]. Chronic hypercapnia contributes to excessive daytime somnolence, headaches, confusion, and eventually coma and death. Somnolence and sleep disorders are very common in myotonic dystrophy (DM) and may be primarily related to a central nervous system process affecting the sleep-wake cycle. Chronic hypercapnia exacerbates somnolence due to other causes $[5,6]$.

Our clinical experience suggests that patients with DM1 receive little benefit from using noninvasive ventilation (NIV) and have poor adherence to NIV therapy. There have been few studies assessing the use of NIV in DM1, and results from these are somewhat conflicting. A recent 10-year follow-up study found that patients who started NIV within a year of meeting local criteria for NIV initiation and who had good 
adherence to treatment had a lower risk of death and significant events, such as invasive ventilation [7]. The criteria for initiation of NIV were symptoms of hypercapnia (dyspnoea, morning headaches, sleep disturbance, diurnal sleepiness) combined with $P_{\mathrm{CO}_{2}}>6 \mathrm{kPa}$, or nocturnal arterial oxygen desaturation. Sleepiness was considered a symptom of either sleep disordered breathing or hypoventilation. Polysomnography was not performed to explore central hypersomnolence as a cause of sleepiness. An earlier study showed a sustained reduction in $P_{\mathrm{CO}_{2}}$ in capillary blood 2 years after initiation of NIV, with the majority of patients reporting increased alertness and improvement in shortness of breath after initiation of NIV [8]. Similar symptomatic benefit was reported from a study in Portugal; however, the majority of patients in this study were started on NIV based on symptoms of hypoventilation rather than hypercapnia, and follow-up daytime blood gases were not affected by NIV [9]. All three of these studies reported issues with adherence to NIV in DM1, with approximately a third of patients averaging $<5 \mathrm{~h}$ per day. Finally, withdrawal of NIV for 1 month was found to cause an increase in $P_{\mathrm{CO}_{2}}$ and deterioration of nocturnal oxygen saturation, but this was not associated with worsening of symptoms of nocturnal alveolar hypoventilation or quality of life [10].

We performed a retrospective service evaluation of patients with DM1 to investigate the impact of NIV on $P_{\mathrm{CO}_{2}}$ measured by capillary blood gas, symptoms of alveolar hypoventilation and adherence to NIV.

\section{Methods}

\section{Patients}

Adult patients with DM1 were identified from the Manchester University NHS Foundation Trust (MFT) North West Ventilation Unit database. Patients with DM2 or other types of myotonia, and those who had never been started on NIV were excluded from the review. Patients with a diagnosis of DM1 who had been started on NIV as stable elective admissions between the years 2005 and 2018 were included in the study.

\section{Data collection}

Retrospective data on capillary blood gas $P_{\mathrm{CO}_{2}}$, lung function (forced expiratory volume in $1 \mathrm{~s}\left(\mathrm{FEV}_{1}\right)$ and forced vital capacity (FVC)) at baseline, daily use of NIV (hours), ventilator settings (inspiratory and expiratory positive airway pressures, IPAP and EPAP), and symptoms of alveolar hypoventilation (daytime somnolence and headaches) were obtained from electronic patient records, clinic letters and patient notes. All blood gas measurements were ear lobe capillary samples taken whilst not on NIV. Patients who reported symptomatic improvement after starting NIV, including more energy, reduced somnolence, fewer headaches and better sleep were classed as having initial benefit of NIV treatment. Data were grouped into episodes, with the first episode being admission to our ventilation unit for NIV set-up. The second episode was discharge from the unit following NIV set-up, and following episodes were follow-up consultant-led clinic visits. The indications for NIV set-up were either: 1) symptoms of alveolar hypoventilation; or 2) capillary $P_{\mathrm{CO}_{2}}>6.5 \mathrm{kPa}$. Patients with symptoms of alveolar hypoventilation and a $P_{\mathrm{CO}_{2}}<6.5 \mathrm{kPa}$ on admission for NIV set-up were pre-designated as the symptom control group. Patients with a $P_{\mathrm{CO}_{2}}$ $>6.5 \mathrm{kPa}$, with or without symptoms of alveolar hypoventilation, were pre-designated as the respiratory failure group. Patients were divided into low $(<1 \mathrm{~h})$, medium $(1-5 \mathrm{~h})$ and high $(>5 \mathrm{~h})$ adherence groups based on the average hours of NIV documented at follow-up appointments.

\section{Statistical analysis}

Statistical analysis was performed using GraphPad Prism version 7 (GraphPad Software Inc, San Diego, CA, USA). Statistical significance was set at 0.05. Parametric data are presented as mean \pm sD, non-parametric data are presented as median (range). Linear regression and Spearman rank correlation were used to analyse correlation between hours of NIV and $P_{\mathrm{CO}_{2}}$ levels. t-test and Mann-Whitney U test were used for comparing results from patients for whom NIV was indicated and not indicated. One-way ANOVA and Kruskal-Wallis tests were used to analyse effect of adherence category (low, medium, high) on $P_{\mathrm{CO}_{2}}$ and other variables. Chi-squared test was used to analyse the relationship between NIV use and variables including: male gender, number reporting symptomatic benefit, discontinuation of NIV or death.

\section{Results}

Patient characteristics on admission for NIV set-up

Forty patients (20 male) with a mean age of $47.8 \pm 12.6$ years, who were commenced on NIV between the years 2005 and 2018, were included in the study (table 1). The mean capillary $P_{\mathrm{CO}_{2}}$ on admission for set-up on NIV was $6.8 \pm 1.2 \mathrm{kPa}$. There was a significant reduction in mean $P_{\mathrm{CO}_{2}}$ on discharge to $5.9 \pm 0.8 \mathrm{kPa}(\mathrm{p}<0.001)$. Noninvasive ventilation was used for a median duration of 7.8 (range 1.0 11.0) $\mathrm{h} \cdot$ day $^{-1}$ during the index admission to establish patients onto NIV. Mean IPAP was $15.9 \pm 4.5 \mathrm{cmH}_{2} \mathrm{O}$ 


\section{TABLE 1 Patient characteristics on index admission for noninvasive ventilation (NIV) set-up}

\begin{tabular}{lcccc} 
& All patients & Respiratory failure & Symptom control only & p-value \\
\hline Subjects $n$ & 40 & 23 & 17 & \\
\hline Age at admission & $47.8 \pm 12.6$ & $47.1 \pm 10.8$ & $48.9 \pm 15.0$ & 0.666 \\
\hline Gender male & $20(50)$ & $11(48)$ & $9(53)$ & 0.749 \\
$P_{\mathrm{CO}_{2}}$ at admission $\mathrm{kPa}$ & $6.8 \pm 1.2$ & $7.5 \pm 1.2$ & $5.9 \pm 0.34$ & $<0.001$ \\
$P_{\mathrm{CO}_{2} \text { on discharge } \mathrm{kPa}}$ & $5.9 \pm 0.8$ & $6.1 \pm 1.0$ & $5.7 \pm 0.40$ & 0.095 \\
\hline $\mathrm{Hours}$ of NIV & $7.8(1.0-11.0)$ & $8.0(1.0-11.0)$ & $7.0(1.0-11.0)$ & 0.825 \\
\hline IPAP $\mathrm{cmH}_{2} \mathrm{O}$ & $15.9 \pm 4.5$ & $17.9 \pm 4.4$ & $13.2 \pm 2.9$ & $<0.001$ \\
\hline EPAP $\mathrm{cmH}_{2} \mathrm{O}$ & $4.1 \pm 1.3$ & $4.1 \pm 1.3$ & $4.0 \pm 1.2$ & 0.752 \\
\hline PS (IPAP-EPAP) & $11.8 \pm 4.2$ & $13.8 \pm 3.9$ & $9.2 \pm 2.9$ & $<0.001$ \\
\hline FEV $\%$ pred & $67 \pm 19$ & $62 \pm 20$ & $70 \pm 20$ & 0.106 \\
\hline FVC $\%$ pred & $67 \pm 20$ & $62 \pm 20$ & $70 \pm 20$ & 0.145 \\
\hline
\end{tabular}

Data are presented as mean \pm SD, $\mathrm{n}(\%)$ or median (range), unless otherwise stated. Values in bold represent statistically significant results. $P_{\mathrm{CO}_{2}}$ : carbon dioxide tension; IPAP: inspiratory positive airway pressure; EPAP: expiratory positive airway pressure; PS: pressure support; $\mathrm{FEV}_{1}$ : forced expiratory volume in $1 \mathrm{~s}$; FVC: forced vital capacity.

and EPAP $4.1 \pm 1.3 \mathrm{cmH}_{2} \mathrm{O}$. There was no correlation between capillary $P_{\mathrm{CO}_{2}}$ on discharge and NIV adherence ( $\mathrm{p}=0.93$ ), or between capillary $P_{\mathrm{CO}_{2}}$ and IPAP or EPAP ( $\mathrm{p}=0.120$ and $\mathrm{p}=0.388$, respectively).

The respiratory failure group comprised 23 out of 40 patients. The mean $P_{\mathrm{CO}_{2}}$ in the respiratory failure group was $7.5 \pm 1.2 \mathrm{kPa}$ on admission and this significantly reduced to $6.1 \pm 1.0 \mathrm{kPa}$ on discharge $(\mathrm{p}<0.001)$. In the 17 out of 40 patients with a $P_{\mathrm{CO}_{2}}<6.5 \mathrm{kPa}$ on admission (symptom control group), the mean $P_{\mathrm{CO}_{2}}$ was $5.9 \pm 0.34 \mathrm{kPa}$ on admission and $5.7 \pm 0.4 \mathrm{kPa}$ on discharge $(\mathrm{p}=0.05)$. In the respiratory failure group (n=23), mean $P_{\mathrm{CO}_{2}}$ reduced from $7.4 \pm 1.2$ on admission to $6.1 \pm 1.0$ on discharge $(\mathrm{p}<0.001)$. Patients in the respiratory failure group were set up with significantly higher IPAP than patients in the symptom control group (17.9 $\pm 4.4 \mathrm{cmH}_{2} \mathrm{O}$ versus $13.2 \pm 2.9 \mathrm{cmH}_{2} \mathrm{O}$, respectively, $\left.\mathrm{p}<0.001\right)$.

\section{Adherence to NIV and $\mathrm{P}_{\mathrm{CO}_{2}}$ levels during follow-up}

Patient characteristics at follow-up are presented in table 2. The number of follow-up appointments patients had varied between 0 and 18, depending on when NIV was started, the frequency of appointments and whether the patient had died, been discharged or lost to follow-up. Follow-up is structured with an initial post-discharge consultant-led review occurring within 4 months. Following discharge with NIV they are supported by access to the multidisciplinary team and advice over the telephone. Consultant-led reviews occur at 6-monthly intervals. Additional reviews are arranged on as required basis if patients are having difficulty tolerating NIV. Following discharge from hospital one patient in the symptom control group returned their ventilator within a month, one patient died and two were lost to follow-up. Thus 36 patients attended for outpatient follow-up. At the first follow-up visit the mean capillary $P_{\mathrm{CO}_{2}}$ was $6.0 \pm 0.8 \mathrm{kPa}$ in the symptom control group and $6.2 \pm 0.8 \mathrm{kPa}$ in the respiratory failure group $(\mathrm{p}=0.130)$. There was no significant change in $P_{\mathrm{CO}_{2}}$ between discharge from the unit and the first follow-up visit $(\mathrm{p}=0.382)$, even though NIV adherence at the first follow-up was significantly lower than during admission $(\mathrm{p}<0.001)$.

\begin{tabular}{lcccc} 
TABLE 2 Patient characteristics at follow-up & & & \\
& All patients & Respiratory failure & Symptom control only & p-value \\
\hline Subjects $\mathbf{n}$ & 36 & 20 & 16 & \\
Average $P_{\mathrm{CO}_{2}}$ at follow-up kPa & $6.1 \pm 0.7$ & $6.3 \pm 0.7$ & $5.8 \pm 0.6$ & 0.012 \\
Hours of NIV & $2.9(0-10.4)$ & $1.8(0-9.7)$ & $3.2(0.3-10.4)$ & 0.484 \\
Number of follow-up visits & $5(1-18)$ & $7(1-18)$ & $5(1-14)$ & 0.464 \\
Months between visits & $4.7(0.3-17.7)$ & $4.4(0.3-17.7)$ & $4.9(1.2-8.0)$ & 0.796 \\
Stopped NIV & $14(39)$ & $7(35)$ & $5(31)$ & 0.813 \\
Felt benefit & $18(50)$ & $8(40)$ & $10(63)$ & 0.180 \\
\hline Somnolence at follow-up & $23(64)$ & $13(65)$ & $10(63)$ & 0.877 \\
\hline
\end{tabular}

Data are presented as mean $\pm \mathrm{sD}, \mathrm{n}(\%)$ or median (range), unless otherwise stated. Values in bold represent statistically significant results. $P_{\mathrm{CO}_{2}}$ : carbon dioxide tension; NIV: noninvasive ventilation. 


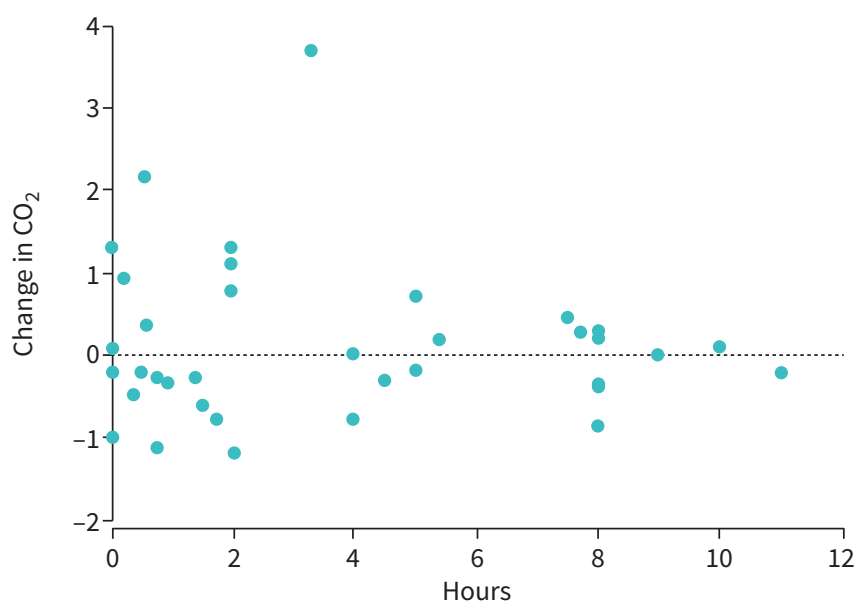

FIGURE 1 Relationship between noninvasive ventilation adherence and change in capillary carbon dioxide at the first follow-up visit.

At the first follow-up visit median NIV adherence was $2.0(0-11) \mathrm{h} \cdot$ day $^{-1}, 4.3(0-10) \mathrm{h}$ in the symptom control group and $1.6(0-11) \mathrm{h}$ in the respiratory failure group $(\mathrm{p}=0.146)$. There was no correlation between change in capillary $P_{\mathrm{CO}_{2}}$ from discharge and NIV adherence at the first follow-up visit ( $\left.\mathrm{p}=0.334\right)$ (figure 1). In total 4/36 (11\%) had discontinued NIV completely, and 24/36 (67\%) had an average NIV adherence $<5 \mathrm{~h} \cdot \mathrm{day}^{-1}$.

Overall patients had 5 (1-18) follow-up visits over $2.6(0.0-10.0)$ years, with visits every $4.7(0.3-17.7)$ months. There was no correlation between adherence to NIV and frequency of follow-up visits ( $\mathrm{p}=0.131)$, and no significant difference in the frequency of visits between the respiratory failure and symptom control groups (11.1 (1-17) months and 12.5 (3-16) months, respectively, $\mathrm{p}=0.771)$. During follow-up 14 out of 36 (39\%) patients stopped using NIV, and two of these were restarted on NIV at a later date. Of the patients who stopped using NIV, 9 out of 14 were in the respiratory failure group. Patients in the respiratory failure group retained a higher mean $P_{\mathrm{CO}_{2}}$ during follow-up than patients in the symptom control only group $(6.3 \pm 0.7$ versus $5.8 \pm 0.6$, respectively, $\mathrm{p}<0.05)$. Changes in mean $P_{\mathrm{CO}_{2}}$ in the two groups during the first 10 episodes are shown in figure 2a. There was no significant difference in NIV adherence between the respiratory failure and symptom control groups during follow-up (1.8 (0-9.7) h versus $3.2(0.3-10.4) \mathrm{h}$, respectively, $\mathrm{p}=0.484$ ) (figure $2 \mathrm{~b}$ ).
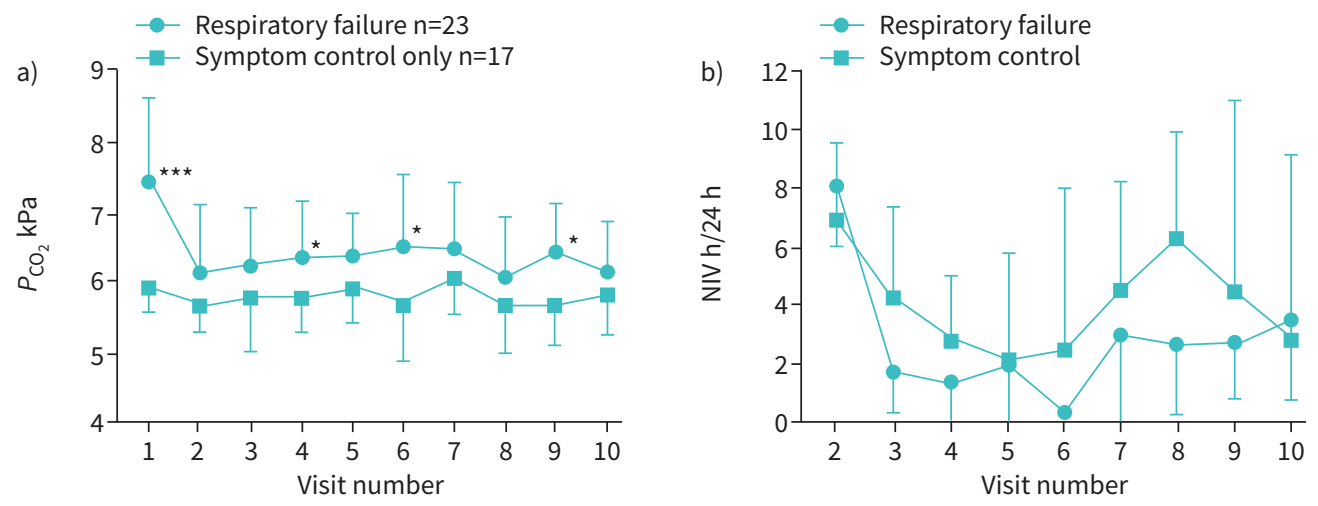

FIGURE 2 a) Changes in carbon dioxide tension $\left(P_{\mathrm{CO}_{2}}\right)$ levels at admission for noninvasive ventilation (NIV) set-up (visit 1), discharge (visit 2 ) and follow-up (visits $3-10$ ). Graph shows mean \pm sD. ${ }^{\star * \star}$ : $p<0.001 ;{ }^{*}: p<0.05$. b) Changes in NIV h per $24 \mathrm{~h}$ at discharge (visit 2) and follow-up visits. Graph shows mean \pm sD. 
TABLE 3 Characteristics of patients who have died after being set-up on noninvasive ventilation (NIV)

\begin{tabular}{|c|c|c|c|}
\hline & Alive & Deceased & $\mathrm{p}$-value \\
\hline Subjects n & 30 & 10 & \\
\hline Age at death & & $54.0 \pm 8.7$ & \\
\hline Age at admission & $45.3 \pm 12.9$ & $52.9 \pm 9.1$ & 0.074 \\
\hline Gender male & $15(50)$ & $4(40)$ & 0.721 \\
\hline NIV indicated & $13(43)$ & $8(80)$ & 0.044 \\
\hline$P_{\mathrm{CO}_{2}}$ at admission & $6.6 \pm 0.8$ & $7.6 \pm 1.6$ & 0.006 \\
\hline$P_{\mathrm{CO}_{2}}$ at follow-up & $6.0 \pm 0.6$ & $6.7 \pm 0.7$ & 0.004 \\
\hline Hours of NIV at follow-up & $3.4(0-10.4)$ & $1.6(0.2-7.9)$ & 0.240 \\
\hline $\mathrm{FEV}_{1} \%$ pred & $71 \pm 19$ & $58 \pm 15$ & 0.074 \\
\hline FVC \% pred & $71 \pm 20$ & $57 \pm 16$ & 0.040 \\
\hline
\end{tabular}

Data are presented as mean \pm sD, $\mathrm{n}(\%)$ or median (range), unless otherwise stated. Values in bold represent statistically significant results. $P_{\mathrm{CO}_{2}}$ : carbon dioxide tension; $\mathrm{FEV}_{1}$ : forced expiratory volume in $1 \mathrm{~s}$; FVC: forced vital capacity.

\section{Mortality}

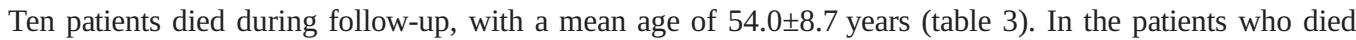
the mean time from being established on NIV to death was $2.9(0.1-5)$ years after NIV set-up. Four out of 10 had discontinued NIV, two had low adherence to $\operatorname{NIV~}\left(<2 \mathrm{~h} \cdot \mathrm{day}^{-1}\right)$ and one had high adherence $\left(8 \mathrm{~h} \cdot\right.$ day $\left.^{-1}\right)$. Mortality was associated with higher $P_{\mathrm{CO}_{2}}$ on admission for set-up and at follow-up compared with surviving patients $(\mathrm{p}<0.01$ and $\mathrm{p}<0.005$, respectively). Furthermore, mortality was associated with worse lung function at time of NIV initiation (FVC $57 \pm 16 \%$ pred versus $71 \pm 20 \%$ pred, $\mathrm{p}<0.05$ ).

\section{Symptoms of alveolar hypoventilation}

On admission for NIV set-up 34 out of 40 (85\%) patients reported symptoms of alveolar hypoventilation (daytime somnolence, early morning headaches). In the symptom control group 16 out of 17 patients reported somnolence, 8 out of 17 headaches and 5 out of 17 dyspnoea. In the respiratory failure group 17 out of 23 patients reported somnolence, 4 out of 23 headaches and 5 out of 23 experienced dyspnoea.

Half (18 out of 36) of the patients in this study reported feeling some symptomatic benefit from NIV at follow-up (table 4). Those with perceived symptomatic benefit used NIV $4.3(0.2-10.4) \mathrm{h}^{-\mathrm{day}^{-1}} \mathrm{during}^{-1}$ follow-up, significantly more than those who did not feel benefit at $1.6(0-8) \mathrm{h} \cdot \mathrm{day}^{-1}(\mathrm{p}<0.05)$, and also had significantly lower $P_{\mathrm{CO}_{2}}$ at follow-up (5.8 (4.9-7.8) and 6.1 (5.5-7.7), respectively, $\left.\mathrm{p}<0.05\right)$. There was no significant difference in $P_{\mathrm{CO}_{2}}$ at admission between the two groups $(\mathrm{p}=0.707)$. Patients who felt benefit of NIV reported excessive daytime somnolence at follow-up at an equal rate to those who did not feel benefit.

Overall 33 out of 40 (83\%) patients reported excessive daytime somnolence at admission, with median capillary $P_{\mathrm{CO}_{2}} 6.5$ (5.1-11.8) $\mathrm{kPa}$ in those with somnolence and 6.9 (6-8.6) $\mathrm{kPa}$ in those without

TABLE 4 Characteristics of patients with and without perceived symptomatic benefit from noninvasive ventilation (NIV)

\begin{tabular}{|c|c|c|c|}
\hline & Symptomatic benefit & No symptomatic benefit & $\mathrm{p}$-value \\
\hline Subjects $n$ & 18 & 18 & \\
\hline Age & $48.6 \pm 14.4$ & $47.3 \pm 11.3$ & 0.750 \\
\hline Gender male & $9(50)$ & $8(44)$ & 0.739 \\
\hline Somnolence at admission & $16(89)$ & $14(78)$ & 0.371 \\
\hline Somnolence at follow-up & $12(67)$ & $12(67)$ & 1.000 \\
\hline$P_{\mathrm{CO}_{2}}$ at admission $\mathrm{kPa}$ & $5.9(5.1-11.8)$ & $6.9(5.5-8.6)$ & 0.707 \\
\hline$P_{\mathrm{CO}_{2}}$ at follow-up $\mathrm{kPa}$ & $5.8(4.9-7.8)$ & $6.1(5.5-7.7)$ & 0.037 \\
\hline NIV hours at follow-up & $4.3(0.2-10.4)$ & $1.6(0-8.0)$ & 0.047 \\
\hline FEV $_{1} \%$ pred & $65 \pm 20$ & $69 \pm 19$ & 0.623 \\
\hline FVC \% pred & $65 \pm 22$ & $69 \pm 19$ & 0.562 \\
\hline \multicolumn{4}{|c|}{$\begin{array}{l}\text { Data are presented as mean } \pm \mathrm{SD}, \mathrm{n}(\%) \text { or median (range), unless otherwise stated. Values in bold represent } \\
\text { statisitically significant results. } P_{\mathrm{CO}_{2}} \text { : carbon dioxide tension; } \mathrm{FEV}_{1} \text { : forced expiratory volume in } 1 \mathrm{~s} \text {; FVC: forced } \\
\text { vital capacity. }\end{array}$} \\
\hline
\end{tabular}




\begin{tabular}{|c|c|c|c|}
\hline & Somnolence at follow-up & No somnolence at follow-up & $\mathrm{p}$-value \\
\hline Subjects $n$ & 24 & 12 & \\
\hline Age & $49.3 \pm 9.5$ & $42.9 \pm 17.7$ & 0.171 \\
\hline Gender male & $11(46)$ & $6(59)$ & 0.813 \\
\hline Somnolence at admission & $22(92)$ & $8(67)$ & 0.058 \\
\hline$P_{\mathrm{CO}_{2}}$ at admission $\mathrm{kPa}$ & $6.6(5.1-11.8)$ & $6.9(6-8.6)$ & 0.470 \\
\hline$P_{\mathrm{CO}_{2}}$ at follow-up $\mathrm{kPa}$ & $6.1(4.9-7.8)$ & $5.8(4.9-7.0)$ & 0.097 \\
\hline NIV hours at follow-up & $1.6(0-9.7)$ & $4.8(0-10.4)$ & 0.038 \\
\hline FEV $_{1} \%$ pred & $65(25-102)$ & $69(32-83)$ & 0.540 \\
\hline FVC $\%$ pred & $63(34-111)$ & $69(27-79)$ & 0.606 \\
\hline
\end{tabular}

( $\mathrm{p}=0.470)$. On follow-up, 24 out of $36(67 \%)$ reported excessive daytime somnolence (table 5). Patients with excessive somnolence used NIV significantly less $\left(1.6(0-9.7) \mathrm{h} \cdot\right.$ day $\left.^{-1}\right)$ than those who did not report somnolence (5.0 (0.3-10.4) h·day $\left.{ }^{-1}, \mathrm{p}<0.05\right)$. Those with somnolence at follow-up had a median $P_{\mathrm{CO}_{2}}$ of 6.1 (4.9-7.8) kPa versus those without somnolence 5.8 (4.9-7.0) $\mathrm{kPa}(\mathrm{p}=0.09)$.

\section{Discussion}

We have observed that patients with DM1 have a significant reduction in $\mathrm{CO}_{2}$ during admission for NIV set-up, and this is maintained at follow-up despite an observed marked reduction in adherence to NIV. There was no correlation between the use of NIV and $P_{\mathrm{CO}_{2}}$ suggesting that the reduction in $P_{\mathrm{CO}_{2}}$ could not wholly be explained by the use of NIV. A proportion of patients were commenced on NIV for symptoms compatible with alveolar hypoventilation, in the absence of a $P_{\mathrm{CO}_{2}}>6.5 \mathrm{kPa}$. We did not identify a difference between adherence to NIV or improvement in symptoms and $P_{\mathrm{CO}_{2}}$ levels. A high $P_{\mathrm{CO}_{2}}$ on admission for set-up on NIV was however associated with higher mortality reflecting more advanced respiratory involvement of DM1.

Low adherence to NIV is well recognised in DM. In our hands $72 \%$ of patients averaged $<5 \mathrm{~h} \cdot$ day $^{-1}$ and over a third discontinued NIV during follow-up. Adherence to NIV did not appear to impact on $P_{\mathrm{CO}_{2}}$ on follow-up, and we noted that in surviving patients $P_{\mathrm{CO}_{2}}$ normalised irrespective of duration of NIV use. The reasons for low adherence are likely to be multifactorial, and include the lack of observed symptomatic benefit, lack of understanding of the role of NIV and problems using the NIV machine [11]. The mask can be uncomfortable to wear, especially when sleeping, and the ventilators can be perceived as noisy, and travelling with them difficult. Many patients with DM have a degree of cognitive impairment, which may affect their ability to use the ventilators, tolerate masks and also to understand the reasons for using NIV. Patients may be unable to fit and remove their mask due to weakness in their hands or arms. It is important to engage families and carers early on to ensure effective treatment and good compliance. Facial weakness and deformity may also affect mask fit, making them uncomfortable or causing air leak.

An important factor affecting adherence to NIV is the lack of symptomatic improvement. Whilst NIV has been shown to significantly improve quality of life in patients with motor neurone disease and other neuromuscular conditions, the impact in DM is more complex [12, 13]. Only half of the patients in this study reported symptomatic benefit after starting NIV, and despite initial benefit, many patients still experienced lack of energy, somnolence and headaches at follow-up. It is well recognised that these symptoms of alveolar hypoventilation are also characteristic symptoms of the condition itself. However, patients who did report symptomatic benefit had significantly higher adherence with NIV and lower $P_{\mathrm{CO}_{2}}$ at follow-up. It is not clear whether patients discontinue NIV because of the lack of symptomatic improvement, or due to other factors.

Our findings would suggest that NIV does not improve symptoms of alveolar hypoventilation in the absence of daytime hypercapnia. Furthermore adherence to NIV in this setting is very poor. Adherence to NIV in DM1 is extremely variable and does not correlate with changes in $P_{\mathrm{CO}_{2}}$. We do however observe that initial set-up on NIV in patients with significant hypercapnia $\left(P_{\mathrm{CO}_{2}}>6.5 \mathrm{kPa}\right)$ results in correction of hypercapnia, although adherence is not maintained at follow-up. Control of hypercapnia $>6.5 \mathrm{kPa}$ may 
have an impact on overall survival. Ten out of 40 patients died during follow-up and mortality was associated with significant hypercapnia on initial set-up and worse lung function as reflected in lower \% predicted $\mathrm{FEV}_{1}$ and FVC.

The aetiology of respiratory failure in $\mathrm{DM}$ is complex including reduced central drive and $\mathrm{CO}_{2}$ insensitivity [4]. The ventilatory response to hypercapnia and experience of symptoms related to hypercapnia may be abnormal thereby reducing the impact of NIV use on symptom control. Adherence to NIV use may therefore be reduced. Our observations would support the view that although there was no correlation between NIV use and longer-term control of $P_{\mathrm{CO}_{2}}$, improved adherence to NIV in the presence of daytime hypercapnia $\left(P_{\mathrm{CO}_{2}}>6.5\right)$ at set-up may impact longer-term survival as described previously [7].

This study has a number of limitations, and it is recognised that this is a retrospective observational review of a cohort of DM1 patients under consideration of NIV set-up. We cannot be certain we have included all patients with DM1 in the study. Variability in the frequency of individual follow-up visits has made accurate assessment of changes in $P_{\mathrm{CO}_{2}}$ and adherence to NIV more difficult. We cannot exclude the impact of the time of day blood gas measurements were taken on the improvement in $P_{\mathrm{CO}_{2}}$ at time of discharge. As an inpatient, changes of ventilator settings are made following overnight monitoring of oximetry and an early morning blood gas measurement. A daytime blood gas measurement is taken prior to discharge, and typically a blood gas measurement was taken for patients not using NIV (although due to the retrospective nature of this study, it is possible a small proportion of patients may have been using NIV at the time of blood gas measurement). It is anticipated that the early morning blood gas is taken whilst using NIV, and hypercapnia due to alveolar hypoventilation has been corrected. However, poor tolerance and adherence to NIV may contribute to a persistent elevated morning $P_{\mathrm{CO}_{2}}$, which may subsequently correct wholly or in part during waking hours. However, our control of hypercapnia in the "respiratory failure group" and better adherence to NIV during the inpatient stay would suggest NIV is at least in part correcting hypercapnia initially and resetting central drive. Hypercapnic respiratory failure in DM1 remains multifactorial. The sustained reduction of $P_{\mathrm{CO}_{2}}$ unrelated to NIV adherence suggests that the initial presentation with elevated $P_{\mathrm{CO}_{2}}$ rise may be related more to impaired central drive and insensitivity to $P_{\mathrm{CO}_{2}}$ rather than other factors including underlying respiratory muscle weakness. In most neuromuscular diseases hypercapnic respiratory failure is directly related to impaired muscle strength, and control of hypercapnia is proportional to the use of NIV. We have not observed this in DM1, which may suggest that the initial presentation in respiratory failure is related to blunted central respiratory drive. Additional factors may impact this such as intercurrent respiratory illnesses and medication. Respiratory muscle weakness will compound respiratory failure over time and increase the risk of sudden deterioration. We anticipate a greater dependence on and relationship to NIV adherence once this occurs.

In conclusion, the results of this single centre retrospective study show that patients with DM under our care have low adherence to NIV over time, and longer-term NIV use does not correlate with daytime $P_{\mathrm{CO}_{2}}$ levels. The complexity and overlap of symptoms of alveolar hypoventilation with those of myotonic dystrophy may well be contributing to the lack of perceived benefit of NIV and therefore low adherence to use. The benefit of using NIV in DM remains unclear. In the presence of normocapnia $\left(P_{\mathrm{CO}_{2}}<6.5 \mathrm{kPa}\right)$ NIV does not appear to offer any benefit, and adherence to NIV use is very low. However, in the presence of hypercapnia $\left(\mathrm{C}_{\mathrm{CO}_{2}}>6.5 \mathrm{kPa}\right)$ use of NIV may offer some symptomatic benefit in those who adhere to use. Furthermore, there may be a mortality advantage in using NIV and concentrating efforts to support adherence in this group. There is a need for high-quality evidence of the benefits of NIV in DM. Results from our centre suggest long-term adherence to NIV is difficult to achieve, and there may be no benefit in initiation of NIV for symptom control in the absence of significant daytime hypercapnia.

Conflict of interest: V. Rautemaa has nothing to disclose. M.E. Roberts has nothing to disclose. A. Bentley has nothing to disclose. T.W. Felton reports grants from the NIHR Manchester Biomedical Research Centre during the conduct of the study and outside the submitted work.

Support statement: T.W. Felton is supported by the NIHR Manchester Biomedical Research Centre.

References

1 Norwood FL, Harling C, Chinnery PF, et al. Prevalence of genetic muscle disease in Northern England: in-depth analysis of a muscle clinic population. Brain 2009; 132: 3175-3186.

2 Lindberg C, Bjerkne F. Prevalence of myotonic dystrophy type 1 in adults in western Sweden. Neuromuscul Disord 2017; 27: 159-162. 
3 weakness in myotonic dystrophy. Am J Respir Crit Care Med 1997; 156: 133-139.

4 Poussel $\mathrm{M}$, Thil $\mathrm{C}$, Kaminsky $\mathrm{P}$, et al. Lack of correlation between the ventilatory response to $\mathrm{CO}_{2}$ and lung function impairment in myotonic dystrophy patients: evidence for a dysregulation at central level. Neuromuscul Disord 2015; 25: 403-408.

5 Laberge L, Begin P, Dauvilliers Y, et al. A polysomnographic study of daytime sleepiness in myotonic dystrophy type 1. J Neurol Neurosurg Psychiatry 2009; 80: 642-646.

6 Dauvilliers YA, Laberge L. Myotonic dystrophy type 1, daytime sleepiness and REM sleep dysregulation. Sleep Med Rev 2012; 16: 539-545.

7 Boussaid G, Prigent $\mathrm{H}$, Laforet $\mathrm{P}$, et al. Effect and impact of mechanical ventilation in myotonic dystrophy type 1: a prospective cohort study. Thorax 2018; 73: 1075-1078.

8 Nugent AM, Smith IE, Shneerson JM. Domiciliary-assisted ventilation in patients with myotonic dystrophy. Chest 2002; 121: 459-464.

9 Monteiro R, Bento J, Goncalves MR, et al. Genetics correlates with lung function and nocturnal ventilation in myotonic dystrophy. Sleep Breath 2013; 17: 1087-1092.

10 O'Donoghue FJ, Borel JC, Dauvilliers Y, et al. Effects of 1-month withdrawal of ventilatory support in hypercapnic myotonic dystrophy type 1 . Respirology 2017; 22: 1416-1422.

11 Boussaid G, Lofaso F, Santos DB, et al. Factors influencing compliance with non-invasive ventilation at long-term in patients with myotonic dystrophy type 1: a prospective cohort. Neuromuscul Disord 2016; 26: 666-674.

12 Bourke SC, Tomlinson M, Williams TL, et al. Effects of non-invasive ventilation on survival and quality of life in patients with amyotrophic lateral sclerosis: a randomised controlled trial. Lancet Neurol 2006; 5: 140-147.

13 Tsolaki V, Pastaka C, Kostikas K, et al. Noninvasive ventilation in chronic respiratory failure: effects on quality of life. Respiration 2011; 81: 402-410. 